\title{
Umbilical cord insertion site in early gestation and development of placenta
}

\author{
Junichi Hasegawa*, Ryu Matsuoka, Kiyotake \\ Ichizuka, Akihiko Sekizawa and Takashi Okai \\ Department of Obstetrics and Gynecology, Showa \\ University School of Medicine, Tokyo, Japan
}

\begin{abstract}
Aim: To study the relation of umbilical cord insertion $(\mathrm{Cl})$ site in early gestation and placental development from the chorion villosum.

Methods: We ultrasonically measured the distance between the internal cervical Os and the $\mathrm{Cl}$ site (CID), the distance between the internal cervical Os and lower placenta edge (PLD), and placental thickness at early (10-12 weeks) and mid-gestation (18-20 weeks).

Results: CID in early gestation (CID-Early) correlated with CID in mid-gestation $\left(r^{2}=0.171 ; P<0.01\right)$. CID-Early correlated with PLD in mid-gestation $\left(r^{2}=0.093\right.$; $\left.P<0.01\right)$. Thickness of chorion villosum or placenta in early gestation did not correlate with that at mid-gestation. Increasing thickness of placenta was significantly higher in long CID-Early $(\geq 20 \mathrm{~mm})$ cases than short cases $(<20 \mathrm{~mm})(\mathrm{P}<0.05)$.

Conclusions: The process of placental development and the placental location are affected by $\mathrm{Cl}$ location at early gestation, and suggests that this process might be affected by poor blood supply from the low uterine segment when $\mathrm{Cl}$ site is close to the internal cervical Os.
\end{abstract}

Keywords: Chorion villosum; connecting stalk; placenta migration; trophotropism; umbilical cord; velamentous cord insertion.

\section{Introduction}

Several studies [1, 2, 6, 9] evaluated the efficacy of the transvaginal scan in detecting umbilical cord abnormali-

\footnotetext{
*Corresponding author:

Junichi Hasegawa, MD, PhD

Department of Obstetrics and Gynecology

Showa University School of Medicine

1-5-8 Hatanodai

Shinagawa-ku

Tokyo

142-8666

Japan

Tel.: + 81-3-3784-8551

Fax: +81-3-3784-8355

E-mail: hasejun@oak.dti.ne.jp
}

ties in early gestation. Monteagudo et al. [8] prenatally diagnosed a velamentous cord insertion (Cl) by ultrasound in the first trimester and recommended that these cases should be deemed high risk. Sepulveda [9] showed the feasibility of prenatal screening for velamentous $\mathrm{Cl}$ at the 11-14 week scan. In our previous study [6], cases with a $\mathrm{Cl}$ site in the lower uterine segment at the first trimester when compared to a normal $\mathrm{Cl}$ site, had a significantly increased frequency of emergency cesarean delivery, velamentous or marginal $\mathrm{Cl}$, placenta accreta, vasa previa, cord prolapse, and placental abnormalities, such as infarction. Thus, we suggest that the sonographic assessment of the $\mathrm{Cl}$ site in the first trimester could improve later pregnancy management.

In addition to the practical significance of early scanning for the $\mathrm{Cl}$ site and the chorion villosum (which has a similar appearance to the later-developing placenta), we suggest that it is important to evaluate the differences in those ultrasonic findings for both $\mathrm{Cl}$ site and placental location between early and mid-gestation and the relation of $\mathrm{Cl}$ site and placental development; this evaluation might clarify the process of placental development.

For this purpose, we examined the relation between $\mathrm{Cl}$ site at early gestation and placental site in mid-gestation. Also, we analyzed the relation among $\mathrm{Cl}$ site, thickness of chorion villosum and placenta at early gestation and mid-gestation, respectively, to speculate the developmental process of the placenta from chorion villosum and its abnormalities.

\section{Methods}

A prospective cohort study was conducted at the Showa University School of Medicine between June and December 2005. A total of 309 pregnant women who planned to deliver at our hospital were enrolled. The ultrasound examination of the cord and chorion villosum or placenta was performed by one obstetrician (J.H.) for approximately $1 \mathrm{~min}$ as a part of routine obstetrical ultrasound. We obtained informed consent from all patients. At early gestation (10-12 weeks), the distance between the internal cervical Os and Cl site (CID-Early) and the thickness of chorion villosum under the $\mathrm{Cl}$ site were measured using Sonovista (Mochida Inc., Tokyo) with a 7.5-MHz mechanical sector vaginal transducer (Figure 1). At mid-gestation (18-20 weeks), the distance between the internal cervical Os and the $\mathrm{Cl}$ site (CID-Mid), the distance between the internal cervical Os and the 


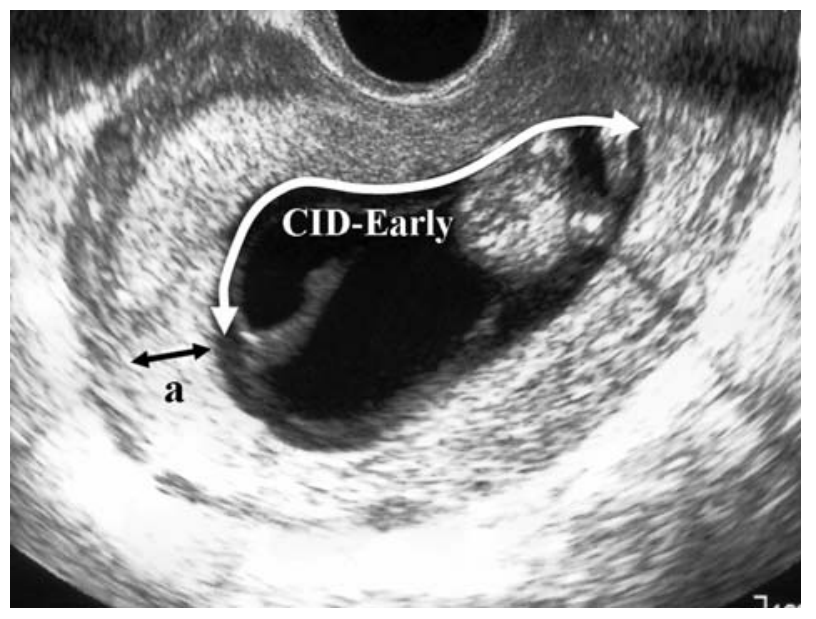

Figure 1 Picture of transvaginal ultrasound measurements: CID-Early was defined as the distance between the cord insertion and internal cervical Os. The thickness of chorion villosum under the cord insertion site was measured (a).

lowest placental edge (PLD-Mid), and the placental thickness under the $\mathrm{Cl}$ site were evaluated using Prosound SSD-3500 (Aloka Inc., Tokyo) equipment with a 5.0-MHz convex abdominal transducer and/or Sonovista with vaginal transducer. In this study internal cervical Os was ultrasonically defined as lowest part of the amniotic space. When these measurements were performed at mid-gestation, the results of the previous measurement at early gestation were blinded to the examiner.

We analyzed the relation between: (1) CID-Early and CID-Mid; (2) CID-Early and PLD-Mid; (3) CID-Early and chorion villosum thickness; (4) thickness of the chorion villosum and the placenta; (5) the difference in increasing thickness of the placenta from the chorion villosum (placental thickness at mid-gestation chorion villosum thickness at early gestation) between short CID-Early $(<20 \mathrm{~mm})$ and long CID-Early $(\geq 20 \mathrm{~mm})$ cases; and (6) respective incidence of placental abnormalities in short and long CID-Early cases. The data were entered into a computerized data analysis program (StatView for Windows, SAS Institute, Inc., Cary, NC). Statistical significance was defined as a $\mathrm{P}<0.05$ using Pearson's correlation coefficient, $t$-test and $x^{2}-$ test, where appropriate.

\section{Results}

Inter-observer coefficients of variations for ultrasonical measurement of distances were $4.5 \pm 2.4 \%$ at early gestation and $4.8 \pm 2.7 \%$ at mid-gestation.

The results of the analysis were as follows;

1. CID-Early significantly correlated with CID-Mid $\left(r^{2}=0.171, P<0.01\right.$; Figure 2).

2. CID-Early significantly correlated with PLD-Mid $\left(r^{2}=0.093, P<0.01\right.$; Figure 3$)$.

3. CID-Early did not correlate with chorion villosum thickness at early gestation (Figure 4).

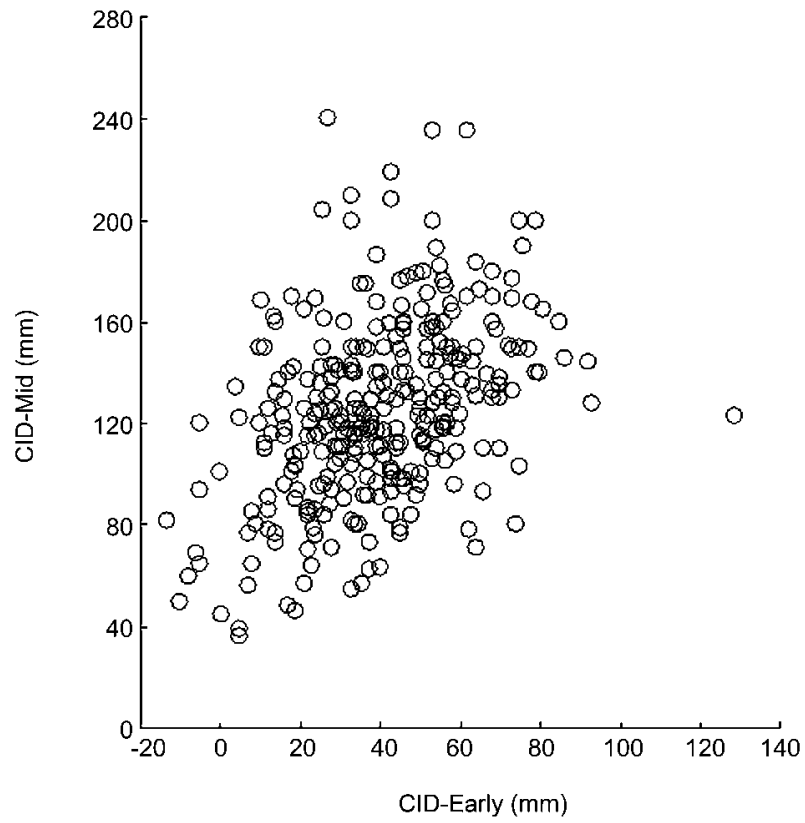

Figure 2 Relationship between CID-Early and CID-Mid. CID-Early significantly correlated with CID-Mid $\left(r^{2}=0.171\right.$, $\mathrm{P}<0.01)$.

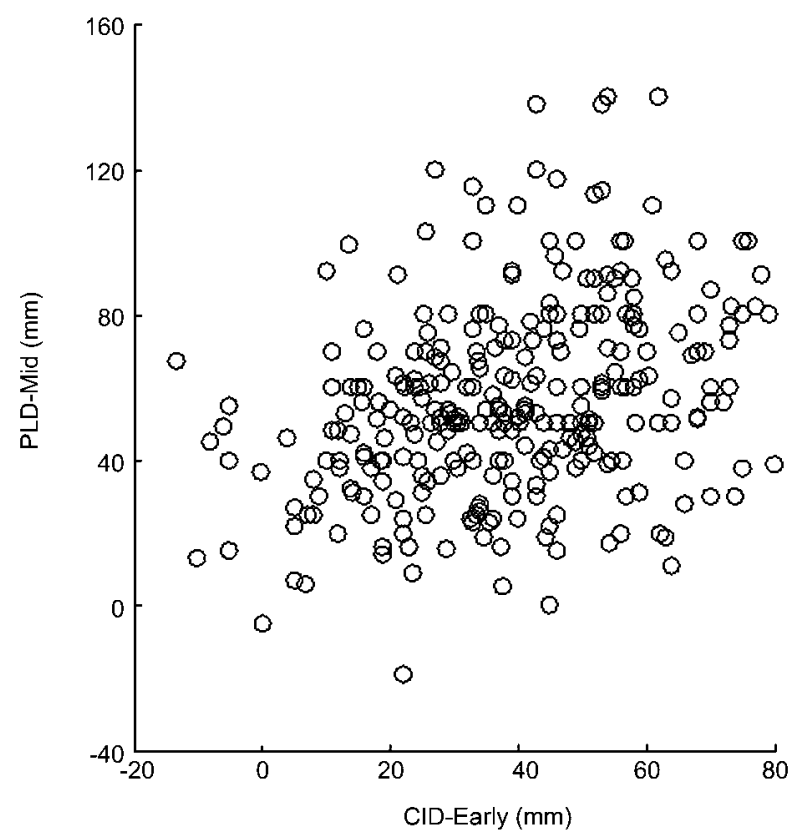

Figure 3 Relationship between CID-Early and PLD-Mid. CID-Early significantly correlated with PLD-Mid $\left(r^{2}=0.093\right.$, $P<0.01)$.

4. Chorion villosum thickness at early gestation did not correlate with placental thickness at mid-gestation (Figure 5).

5. Increasing thicknesses of the placenta from chorion villosum were $46.4 \pm 10.0 \mathrm{~mm}(\mathrm{n}=48)$ and $68.0 \pm$ 


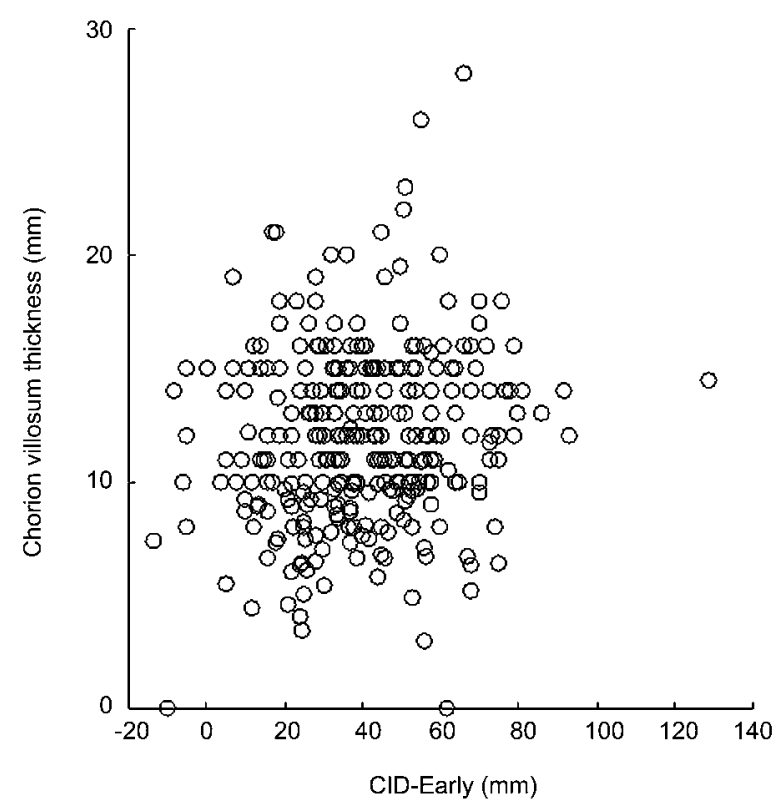

Figure 4 Relationship between CID-Early and chorion villosum thickness.

CID-Early did not correlate with chorion villosum thickness at early gestation.

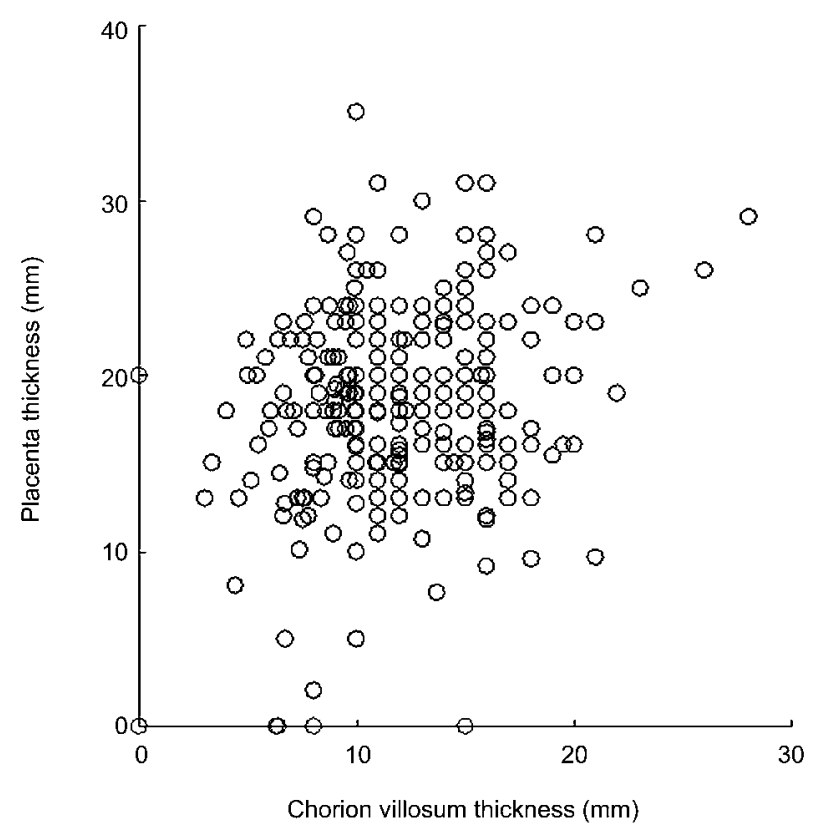

Figure 5 Relationship between chorion villosum thickness at early gestation and placenta thickness at mid-gestation.

Chorion villosum thickness at early gestation did not correlate with placental thickness at mid-gestation.

4.1 mm $(n=261)$ in short and long CID-Early cases, respectively $(P<0.05)$.

6. Placenta previa and low-lying placentas developed in five (10\%; one previa and four low-lying placentas) of 51 short CID-Early cases $(<20 \mathrm{~mm})$; however, neither placenta previa nor low-lying placenta developed in 258 long CID-Early cases $(\geq 20 \mathrm{~mm})(P<0.01)$. Velamentous Cls were observed in two (4\%) of 51 short CID-Early cases and in four (1.6\%) of 258 long CIDEarly cases (NS).

\section{Discussion}

The mechanisms determining placental location and umbilical Cl are unknown; however, Sepulveda [9] considered that these events most probably are operative from the first trimester. One theory [7] is trophotropism, in which chorion villosum or the early placenta "migrates" with advancing gestation to ensure a better blood supply from a more richly vascularized area.

The chorion villosum and the $\mathrm{Cl}$ site can be visualized using transvaginal ultrasonography. In this study, the tendency in which CID-Early correlated with CID-Mid as well a with PLD-Mid was seen. These results may support the hypothesis that the placenta develops around the $\mathrm{Cl}$ site and placental location may be primarily determined by the $\mathrm{Cl}$ site. Actually, when CID-Early was $<20 \mathrm{~mm}$, placenta previa and low-lying placenta frequently occurred. However, it was found that these relations between early and mid-gestation were poor, in contradiction to our predictions. In our previous study [6] of cases with $\mathrm{Cl}$ located at lower uterine segment during the first trimester, $89 \%$ had a normal $\mathrm{Cl}$ site at delivery. The reasons for these poor correlations is explained by the distance between the placenta and internal cervical Os that becomes exponentially long concomitant with uterine growth and dilatation of the uterine isthmus, and by the relatively limited validities of the measures in any predictive manners, and by trophotropism that affected placenta developments.

In our previous studies [4, 6], some vascular and placental structural abnormalities, such as velamentous Cls, abruptio placentae, placenta accreta, accessory placentas, or placental infarctions, were frequently seen in cases with a lower $\mathrm{Cl}$ site at early gestation. Moreover, in cases with a velamentous $\mathrm{Cl}$, our previous studies [3, 5] confirmed that the length of velamentous vessels were significantly longer in lower segment insertions. Monie [7] theorized that velamentous $\mathrm{Cl}$ arise from oblique orientation of the blastocyst at the time of implantation and obliquity of implantation resulted in the body stalk attachment being located away from the definitive placenta. It seems, however, plausible to us from the results of this study, that the above-mentioned phenomenon occurred due to poor blood supply at the lower uterine segment, namely by trophotropism. Actually, our one case without chorion villosum under the $\mathrm{Cl}$ (a suspicious velamentous $\mathrm{Cl}$ ) located at the middle uterine body in early gestation developed into a normal placenta under the $\mathrm{Cl}$ site at 

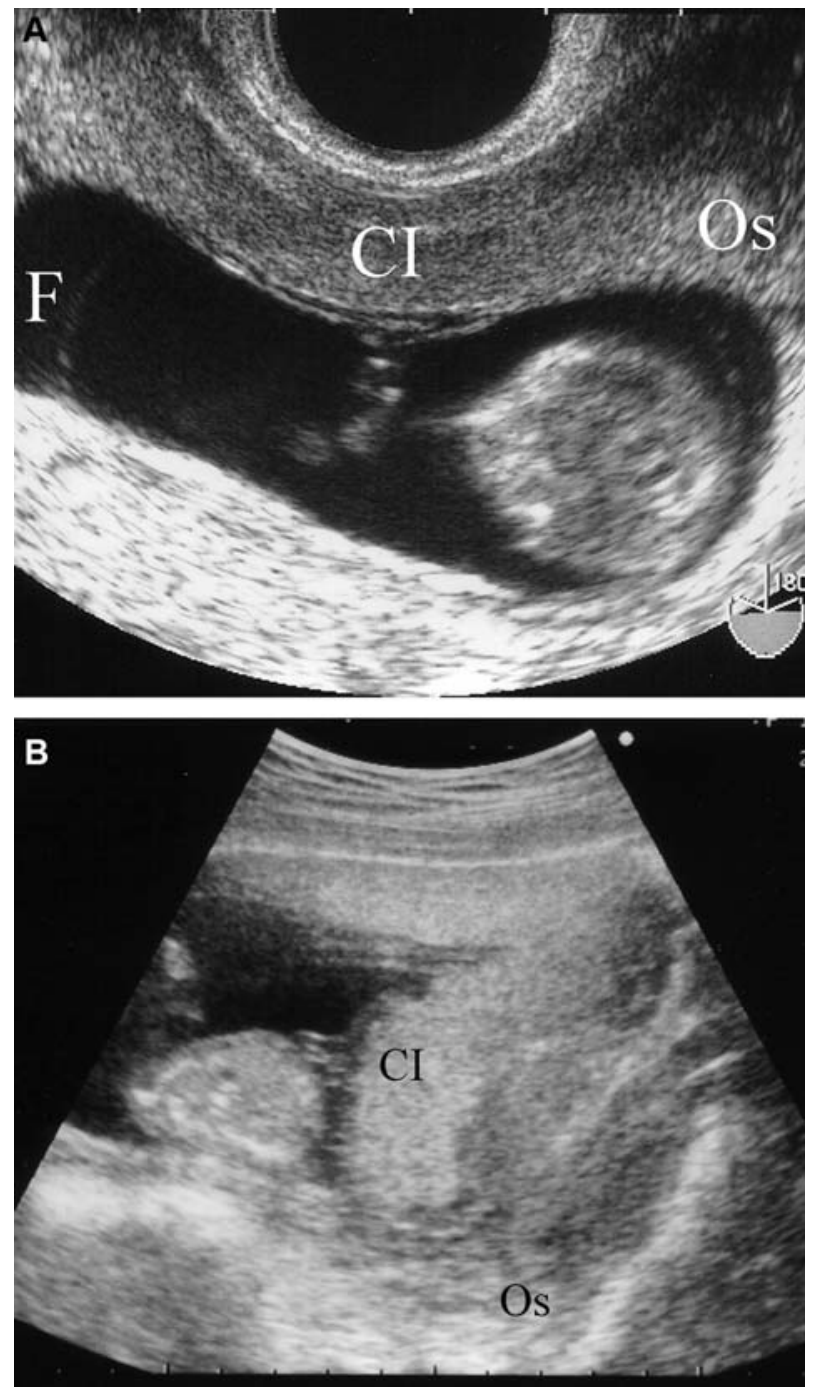

Figure 6 (A) Transvaginal ultrasound image of cord insertion at 11 weeks of gestation: Umbilical cord inserted into the anterior middle uterine wall $(\mathrm{Cl})$. No apparent chorion villosum under the $\mathrm{Cl}$ site was visualized. Os: internal cervical Os; F: fundus.

(B) Transabdominal ultrasound image of the placenta and cord insertion site at 16 weeks of gestation: A normal placenta $(P)$ and cord insertion $(\mathrm{Cl})$ site were visualized on the anterior wall.: internal cervical Os.

mid-gestation (Figure 6). Such episodes might support the trophotropism theory.

Localization of the $\mathrm{Cl}$ site at early gestation would provide the approximate location of the $\mathrm{Cl}$ and the placenta at mid-gestation. However, a chorion villosum at early gestation does not always develop into a placenta as frequently seen; this phenomenon might be because placental development is dependent upon blood supply. This hypothesis is supported by our findings that chorion villosum thickness at early gestation did not correlate with placental thickness at mid-gestation, and that increasing thickness of placenta from chorion villosum was larger in cases of normal $\mathrm{Cl}$ site than in cases of lower $\mathrm{Cl}$ site at early gestation.

\section{Conclusion}

In view of our ultrasound findings, this study supports the trophotropism theory. We think that the process of placental development and the placental location are mainly affected by $\mathrm{Cl}$ location in early gestation and blood supply from uterine wall after early gestation. Normal Cls in early gestation inserted into mid-uterine body mostly develop into normal placentation and normal $\mathrm{Cl}$, but some of the lower Cls in early gestation develop into low-lying placenta and abnormal $\mathrm{Cl}$ of the placenta. When the $\mathrm{Cl}$ site is located at a region with poor blood supply such as the lower uterine segment in early gestation, it is estimated that the complications of pregnancy such as abnormal $\mathrm{Cl}$ or abnormal placentation become more frequent. In these pregnant women, precise ultrasound assessments are required during pregnancy and precise management as a high-risk pregnancy is needed during delivery.

\section{Acknowledgements}

This study was supported in part by Grants-in-Aid for Scientific Research from the Ministry of Education, Culture, Sport, Science and Technolgy of Japan (No. 80365775).

\section{References}

[1] Axt-Fliedner R, Schwarze A, Kreiselmaier P, Krapp M, Smrcek J, Diedrich K. Umbilical cord diameter at 11-14 weeks of gestation: relationship to nuchal translucency, ductus venous blood flow and chromosomal defects. Fetal Diagn Ther. 2006;21:390-5.

[2] Ghezzi F, Raio L, Di Naro E, Franchi M, Bruhwiler H, D’Addario $\mathrm{V}$, et al. First-trimester sonographic umbilical cord diameter and the growth of the human embryo. Ultrasound Obstet Gynecol. 2001;18:348-51.

[3] Hasegawa J, Matsuoka R, Ichizuka K, Sekizawa A, Farina A, Okai T. Velamentous cord insertion and atypical variable decelerations with no accelerations. Int J Gynaecol Obstet. 2005;90:26-30.

[4] Hasegawa J, Matsuoka R, Ichizuka K, Sekizawa A, Okai T. Velamentous cord insertion: significance of prenatal detection to predict perinatal complications. Taiwan $\mathrm{J}$ Obstet Gynecol. 2006;45:21-5.

[5] Hasegawa J, Matsuoka R, Ichizuka K, Sekizawa A, Farina A, Okai T. Velamentous cord insertion into the lower third of the uterus is associated with intrapartum fetal heart rate abnormalities. Ultrasound Obstet Gynecol. 2006;27:425-9. 
[6] Hasegawa J, Matsuoka R, Ichizuka K, Otsuki K, Sekizawa $A$, Farina $A$, et al. Cord insertion into the lower third of the uterus in the first trimester is associated with placental and umbilical cord abnormalities. Ultrasound Obstet Gynecol. 2006;28:183-6.

[7] Monie IW. Velamentous insertion of the cord in early pregnancy. Am J Obstet Gynecol. 1965;93:276-81.

[8] Monteagudo A, Sfakianaki AK, Timor-Tritsch IE. Velamentous insertion of the cord in the first trimester. Ultrasound Obstet Gynecol. 2000;16:498-9.
[9] Sepulveda W. Velamentous insertion of the umbilical cord: A first-trimester sonographic screening study. J Ultrasound Med. 2006;25:963-8; quiz 70.

The authors stated that there are no conflicts of interest regarding the publication of this article.

Received September 2, 2008. Revised February 17, 2009. Accepted March 5, 2009. Previously published online June 3, 2009. 